\title{
Didactic Tools for Education of Embedded Systems
}

\author{
Michal Kelemen ${ }^{1, *}$, Tatiana Kelemenová ${ }^{2}$, Ivan Virgala ${ }^{1}$, Lubica Miková ${ }^{1}$, Tomáš Lipták ${ }^{1}$, Vladislav Maxim ${ }^{3}$ \\ ${ }^{1}$ Department of Mechatronics, Technical University of Kosice, Faculty of Mechanical Engineering, Kosice, Slovakia \\ ${ }^{2}$ Department of Biomedical Engineering and Measurement, Technical University of Kosice, Faculty of Mechanical Engineering, \\ Kosice, Slovakia \\ ${ }^{3}$ Department of Automation, Control and Human Machine Interaction, Technical University of Kosice, Faculty of Mechanical \\ Engineering, Kosice, Slovakia \\ *Corresponding author: michal.kelemen@tuke.sk
}

Received September 09, 2014; Revised September 15, 2014; Accepted October 08, 2014

\begin{abstract}
Paper deals with didactic tools for education of embedded systems on the base of microcontroller family Basic Atom. Microcontrollers are included into products with the aim to improve product properties and with aim to add new functions to product. Several modules have been developed as didactic tools for students training with microcontroller applications. Some educational models with microcontroller also have been developed by students.
\end{abstract}

Keywords: didactic tools, education, embedded system, microcontroller

Cite This Article: Michal Kelemen, Tatiana Kelemenová, Ivan Virgala, Lubica Miková, Tomáš Lipták, and Vladislav Maxim, "Didactic Tools for Education of Embedded Systems." American Journal of Mechanical Engineering, vol. 2, no. 7 (2014): 204-208. doi: 10.12691/ajme-2-7-7.

\section{Introduction}

Actually, there are many types of microcontrollers, which have almost unlimited potential for product properties improving. However, microcontrollers enable to raise totally new products [1].

Microcontrollers have a miniature dimensions and it enables to integrate inside to products. It belongs to group of embedded systems, which have main role - controlling of product activity and man-machine interface between product and user. These products are user friendly and microcontroller helps to user with successful using of products. Microcontroller is very flexible and it is possible to rewrite new program into its memory.

Our students use microcontroller Basic Atom Pro28-M for practical parts of subject "Microcontroller systems" [2].

\section{Microcontroller Properties}

The BasicATOM Pro 28-M is a self contained microcontroller designed for demanding embedded system use. It is built upon the Hitachi HD64F3694GFYV processor and is designed to be pin-compatible to both the BasicATOM 28-M module and the Basic Stamp 2 line of modules.

The BasicAtom Pro 28-M has 32KB of Flash memory useful for user program and 2058B of RAM memory for variables and program running. There is a also 4096B of EEPROM memory for saving of datas. There are 20pins for user applications and 8 pins can be used for $A D$ conversion of analogues input signal (Figure 1). Clock frequency is defined to $16 \mathrm{MHz}$. This microcontroller is able to do 100,000 instructions per second. On the
BasicATOM Pro the IPS is the average basic instructions per second of all the basic instructions that do not have inherent delays in them (pause, serin, serout etc are excluded from the calculation since their internal delays are part of their function). Some commands can run over 500,000 IPS and some much slower (i.e. floating point divides) [2].

Also there are several types of interfaces like UARTS (Universal Synchronous / Asynchronous Receiver and Transmitter), I2C, and One Wire interface (Figure 1).

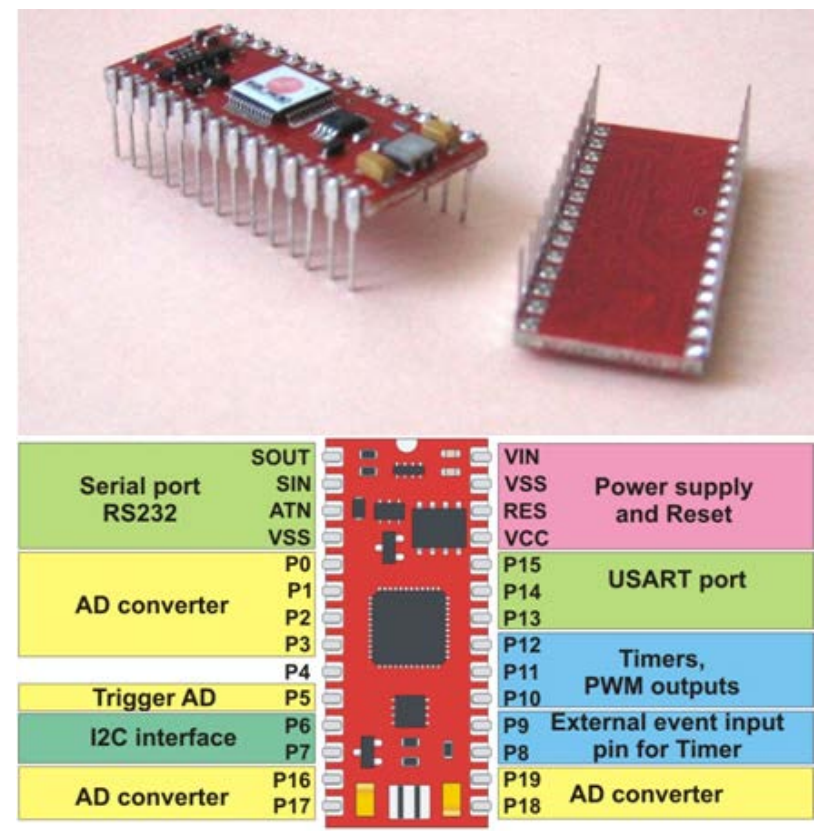

Figure 1. Pin Assignment Overview [2]

The BasicATOM's command language is programmed using a convenient Basic-like compiler which runs on a 
PC. This special version of Basic, called MBasic, is very powerful and easy to use. MBasic comes bundled with an Integrated Development Environment (IDE) offering programming and debugging tools [2].

As with most BASIC implementations, Mbasic includes a full complement of math and comparison functions. MBasic supports 32 bit integer math, both signed and unsigned. It also supports floating point math, signed or unsigned. A signed value denotes whether the resulting value is positive or negative. Floating point math can be processor intensive. This should be remembered any time making a decision when creating programs with math functions. There are numerous cases where floating point math is required. Hence the flexibility of the BasicATOM when compared to other available processors [2].

\section{Microcontroller Usage}

The BasicATOM Pro 28-M can be programmed from a simple RS232 serial port (Figure 2). Only 4 connections to a RS232 DB9 cable are required. You can also use a USB to serial adapter or a Basic Micro development board.

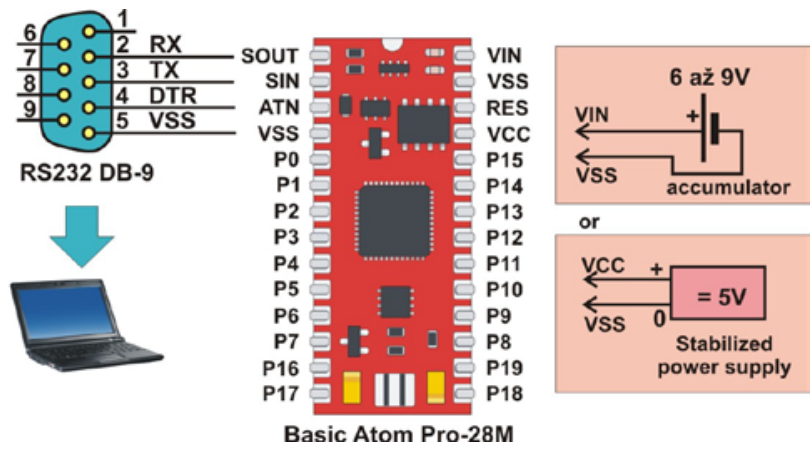

Figure 2. RS232 Programming Interface [1]

Maximum current on user pins are limited to $3 \mathrm{~mA}$ sink, $3 \mathrm{~mA}$ source. Total current for all pins should not exceed $45 \mathrm{~mA}$ sink and $40 \mathrm{~mA}$ source.

Microcontroller user pins work with TTL logic (Figure 3) and pins P6 and P7 work with 3.3V logic (preferred for I2C). Pins P6 and P7 are tolerant to 5V TTL logic. Pins SOUT, SIN and ATN are reserved for inverted RS-232 logic.
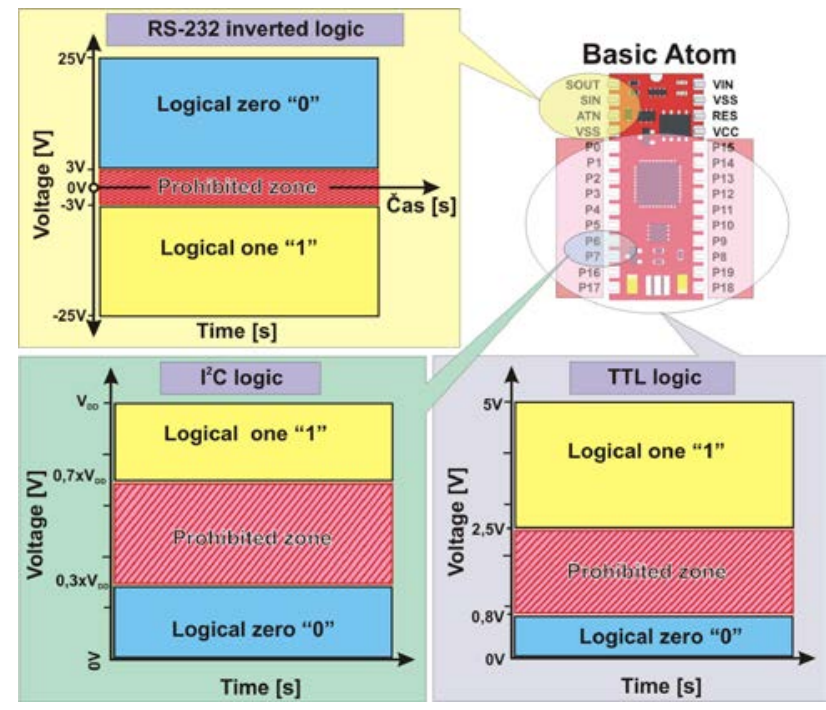

Figure 3. Expression of logical values [1]
Microcontroller is electrostatic sensitive device. So manipulation with it should be very careful. Especially caution is polarity and value of power supply. Reversal of poles of power supply is a reason of microcontroller damage. Any protection circuit is necessary to use for this purpose.

\section{Didactic Tools for Education of Embedded Systems}

The design of embedded systems based on microcontroller has to be trained on practical devices, because of difficult of these systems. The amounts of modules for fast prototyping have been developed (Figure 4).

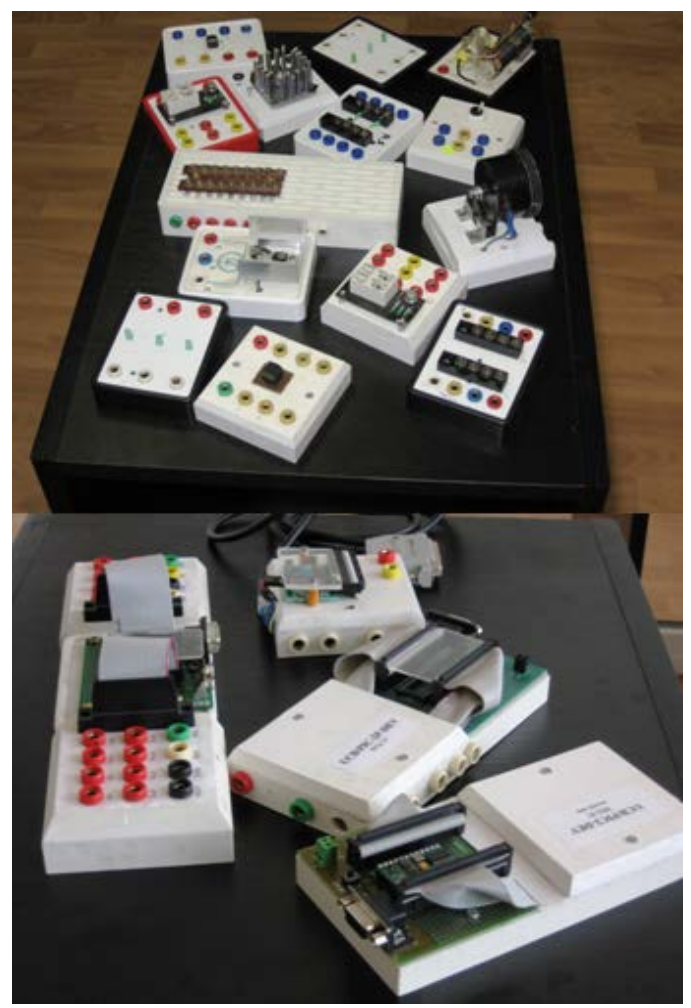

Figure 4. Prototyping modules for education of embedded systems based on microcontrollers

These modules enable quickly realisation of designed embedded system without PCB (Printed circuit boards) making and soldering. Students have more time for experiments and programming of microcontrollers.

Fast built prototype of control system (Figure 5) helps to understand to students these basic principles of controlling. Many bachelor thesis and master thesis use the control system based on microcontroller.

Educational model of manipulator with 5DOF (degree of freedom) uses control system based on microcontroller (Figure 6). The model contains mechanical arms coupled with rotation joints and actuated with hobby servos controlled via using the microcontroller. Position sensors give the feedback information to the microcontroller. End effector enable to hold small objects with weight up to 20 grams. This model contains printed circuit board with microcontroller and it enables to make some experiments. Overall board is reconfigurable based on jumpers and connectors for building of various circuits. The model of 
manipulator also contains the own power supply and base plate. The model also contains several protection devices as prevention of damaging of the model.

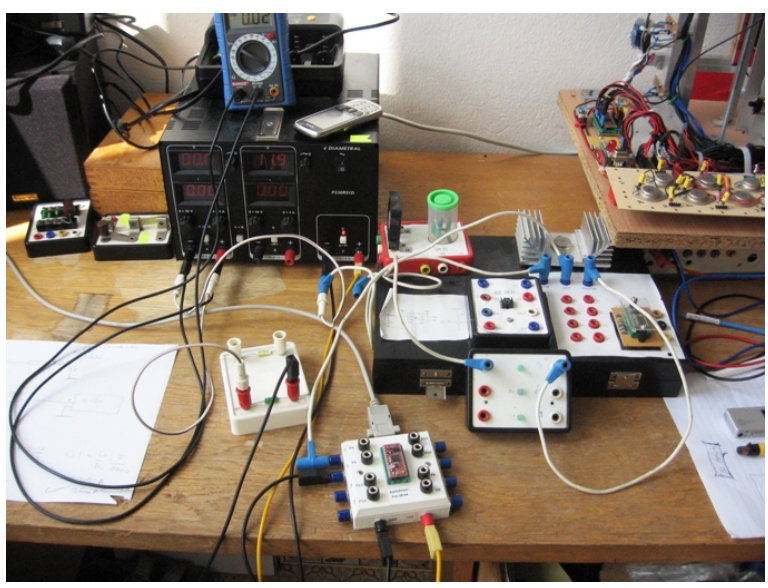

Figure 5. Development of prototype of controll systems using the microcontroller modules

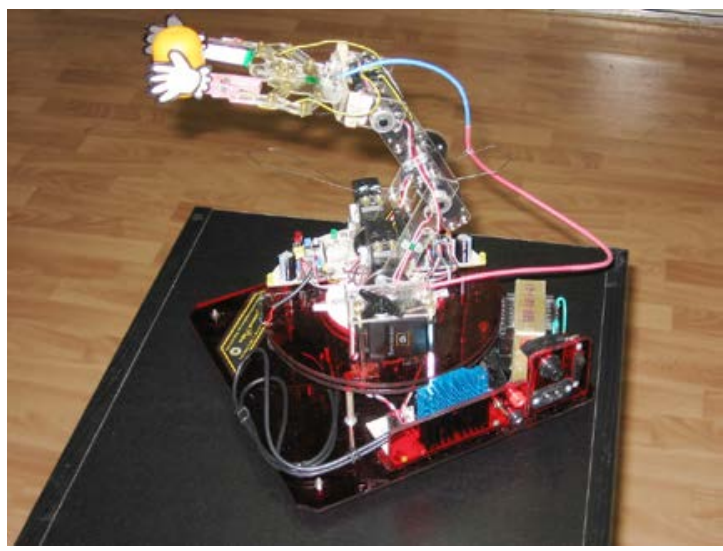

Figure 6. Educational model of manipulator with 5DOF (degree of freedom)

The four legged robot (Figure 7) has been built as master thesis. Microcontroller is used for driving of the eight servos actuating the legs. Locomotion of this robot is complicated because of the centre of gravity has to be moved during the locomotion.

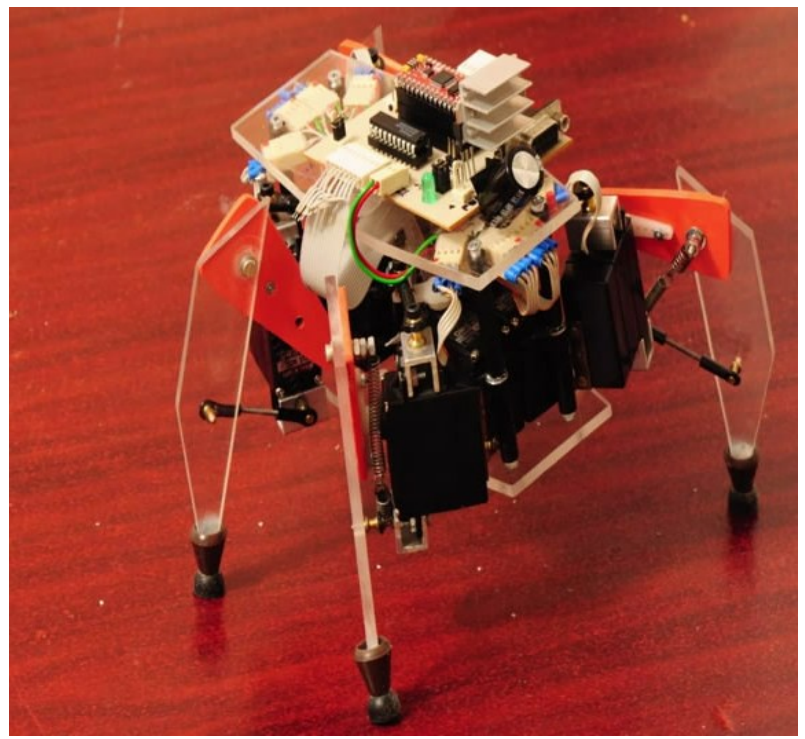

Figure 7. Educational model of four legged robot with microcontroller
Educational model of cartesian manipulator XYZ (Figure 8) is as result of master thesis. It is atypical construction, because the all systems are placed on two pillars. Position in all axes is sensed with position sensors.

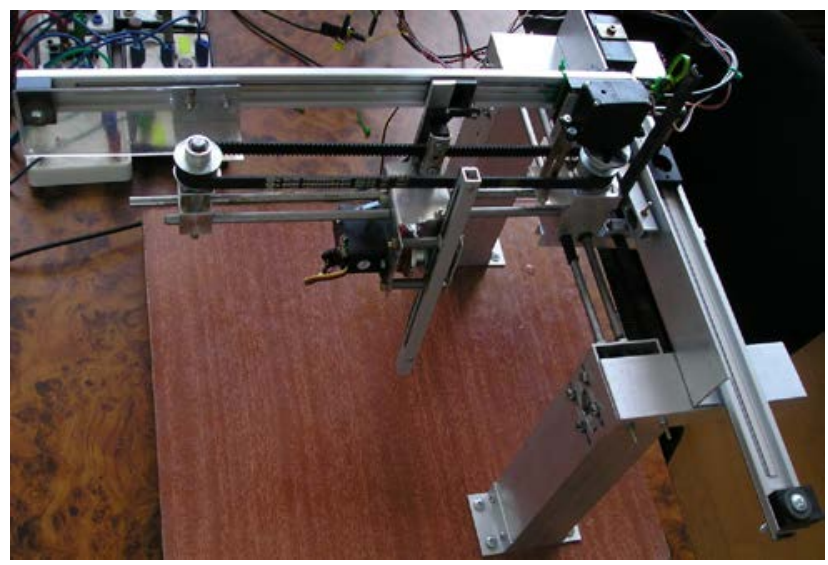

Figure 8. Educational model of cartesian linear XYZ manipulator with microcontroller

Snake-like robot (Figure 9) has been developed by student in another master thesis. It contains eight actuator controlled with microcontroller placed inside the head of the robot. Power supply - accumulator is placed inside the tail of the robot. The student has to solve a several problems as precision cutting and bending of metal plate. Also leading of wires was a big problem in this thesis.

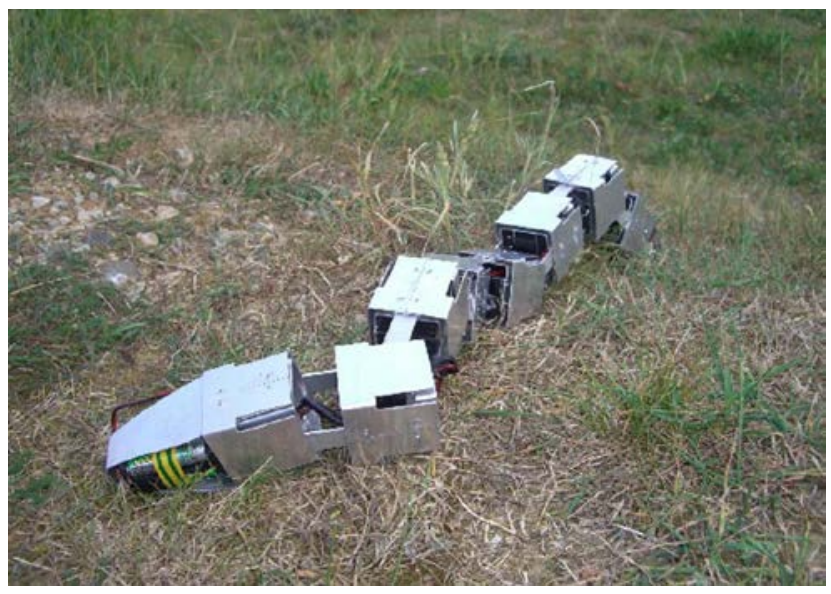

Figure 9. Educational model of snake-like robot with microcontroller

Didactic model of the lift (Figure 10) is result of four master theses. The lift is a miniaturized true copy of real lift. It contains four floors with sliding doors actuated with small servos. Push buttons at every floor enable to call lift cabinet. Led diodes signalize at every floor the position of the cabinet. The cabinet position is sensed with optical tracking infrared sensors. Every door contains security system with optical sensors. Door cannot be close if something is inside the door place. The cabinet contains weight sensor and it gives the information about passengers inside the cabinet. Also LED light lights inside the cabinet only if somebody (or more precisely something) is inside the cabinet. The cabinet contains emergency stop end switches as prevention of cabinet damaging in the lowest and highest position. These emergency switches immediately interrupt power supply in case of bad program made by students. Model is controlled with two microcontrollers cooperated together. 
Overall design is reconfigurable so students could build also own control systems and it is possible to make another activities. All systems is powered with low voltage up to $12 \mathrm{~V}$, because of ensuring of student safety [3].

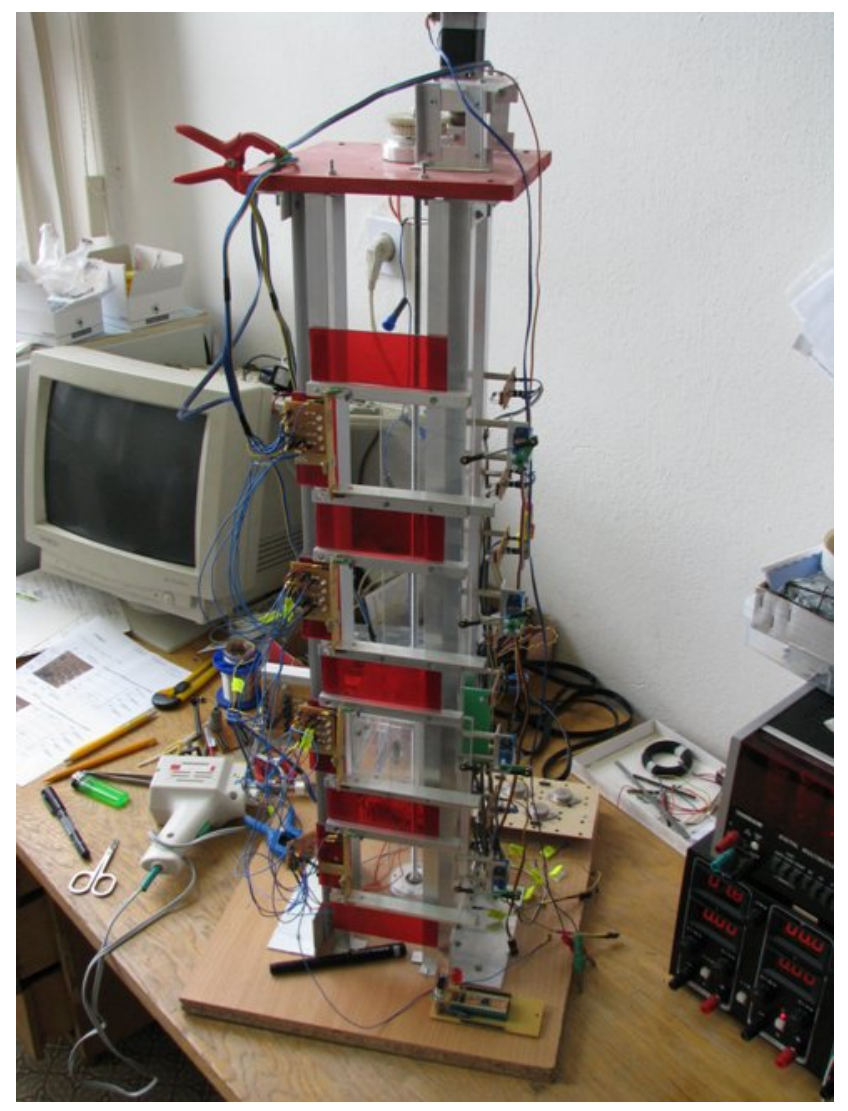

Figure 10. Educational model of lift controlled with microcontroller

Pair of sumo robots (Figure 11) has been developed for robotic competition. The main task of robot is to force out of rival robot from competition ring. These robots contain several sensors for identification of rival robot and sensor for sensing of ring border. Microcontroller contains the program with strategy "how force out the rival robot". Students organize the competition on exercises. Our mechatronic team attends the competition "Robotic day 2013" in category "Mini sumo robot" and we have been awarded with $2^{\text {nd }}$ place.

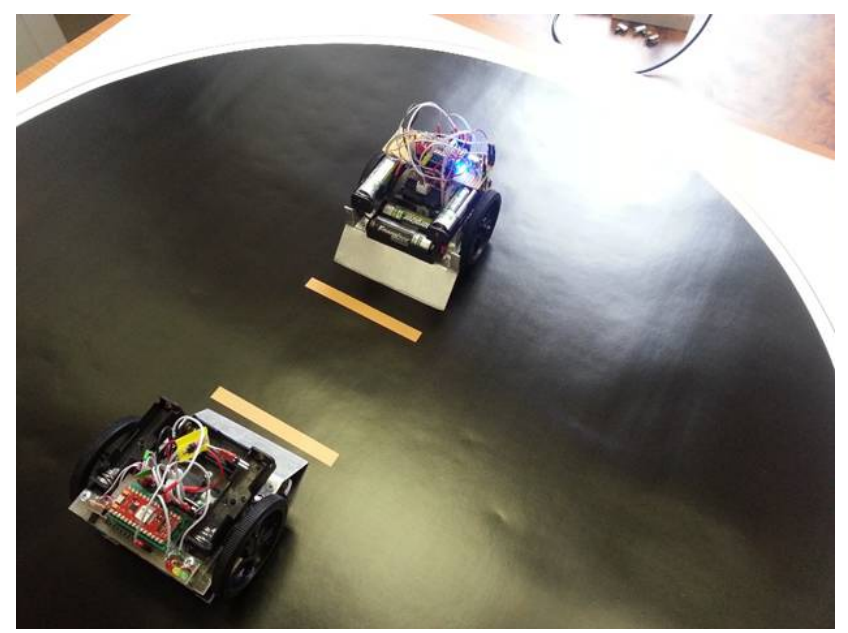

Figure 11. Mini sumo robot controlled with microcontroller
Didactic model of hovercraft (Figure 12) has been developed in another master thesis. Four blowing engines powered the model. The model is controlled with microcontroller and radio. It has ultrasonic sensors for obstacle avoiding.

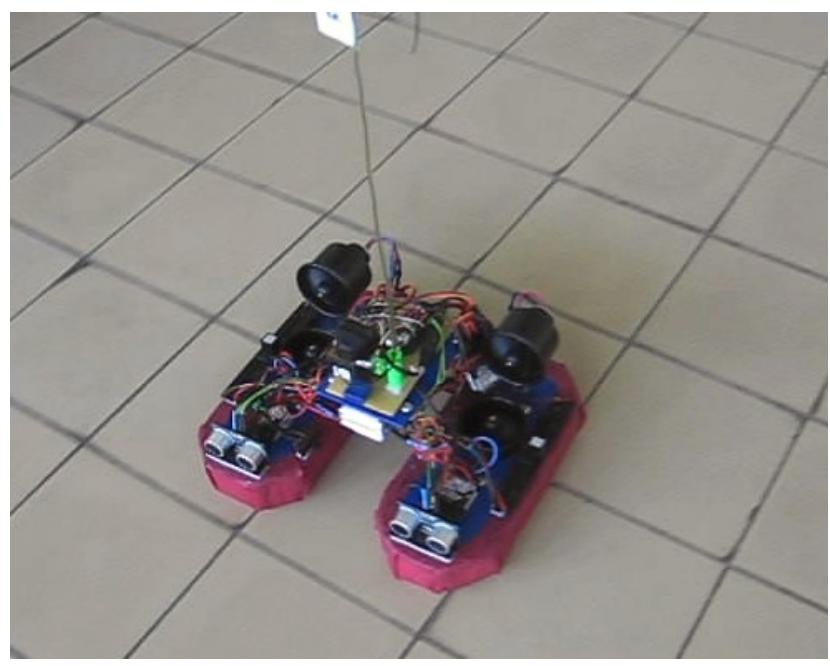

Figure 12. Hovercraft controlled with microcontroller

\section{Conclusion}

All didactic tools help to students on practical exercises. Students receive practical experiences and skills and they are better prepared for real problem solving in practice. Our mission is to prepare students for real world problems. Mechatronics has to goes through the hands of our students and students became to skilled designer and they do not afraid for new ideas [4-13].

\section{Acknowledgement}

The authors would like to thank to Slovak Grant Agency - project KEGA 048TUKE-4/2014 and VEGA $1 / 1205 / 12$. Paper is the result of the Project implementation: University Science Park TECHNICOM for Innovation Applications Supported by Knowledge Technology, ITMS: 26220220182, supported by the Research \& Development Operational Programme funded by the ERDF.

\section{References}

[1] Bradley, D., What is Mechatronics and Why Teach It?, Int. J. of Electrical Eng. Education, 41, (2004), pp. 275-291, 2004.

[2] Basic Micro, Basic Micro Studio Syntax Manual - Basic Micro Studio Reference Manual. Version 2.1. [online]. [cit. 2014-10-12]. available online: <http://downloads.basicmicro.com/downloads/ datasheets/reference_manual_V2_1.pdf

[3] Kelemen, M., Fabian, M., Kelemenová, T., Design and Development of Lift Didactic Model Within Subjects of Mechatronics, Procedia Engineering, Volume 48, 2012, pp. 280286.

[4] Vitko, A., Jurišica, L., Babinec, A., Duchoň, F., Kl'účik, M., Some Didactic Problems of Teaching Robotics, Proceedings of the 1st International Conference Robotics in Education 2010. Bratislava, 16.-17. 9. 2010, Bratislava, Slovak University of Technology in Bratislava. (2010), pp. 27-30.

[5] Koniar, D., Hargaš, L., Hrianka, M., The application of DICOM 7th standard in LabView, Proc. of Biom. Eng., Kladno (2007). 
[6] Ostertagová, E., Computer aided teaching of math at FEI TU in Košice, In: Proceeding of Int. Conf. on Inovation Process in Elearning, Bratislava, March, 10th (2011). pp. 1-5.

[7] Pyszko, R., Koval, L., Machackova, A., Kleckova, Z., Jedlicka, Z., Embedded control system of apparatus for measurement of thermal conductivity, Proceedings of the 7th WSEAS International Conference on Automatic Control, Modeling and Simulation, (2005), pp. 113-117

[8] Acar, M., Parkin, R. M., Engineering Education for Mechatronics, IEEE Trans. on Industrial Electronics, vol. 43, no. 1, (1996), pp. 106-112.

[9] Pásztó, P., Hubinský, P., Mobile Robot Navigation Based on Circle Recognition, Journal of Electrical Engineering, Vol. 64, No. 2 (2013), 84-91.
[10] Baláž, V., Ostertagová, E., Palaščáková, D., Using of e-learning for teaching extension at KVTaR, Acta Mechanica Slovaca. Vol.. 10, No. 2-A (2006), pp. 47-50.

[11] Vitko, A., Jurišica, L., Klúčik, M., Duchoň, F., Context Based Intelligent Behaviour of Mechatronic Systems, Acta Mechanica Slovaca. Vol. 12, No. 3-B. (2008) pp. 907-916.

[12] Hargaš, L., Hrianka, M., Koniar, D. and Izák P., Quality Assessment SMT Technology by Virtual Instrumentation, Applied Electronics 2007, Pilsen, 5. - 6. 9. 2007, (2007).

[13] Yemei Qin, Bo Yu, Heuristic Education of Microcontroller Unit Principle and Applications, Procedia Engineering, Volume 24, 2011, pp. 708-712. 